\title{
Benzetimli Tavlama Algoritması İle Eksik Veri Tamamlama
}

\author{
Serkan METIN* \\ Yönetim Bilişim Sistemleri Bölümü, Sosyal ve Beşeri Bilimler Fakültesi, Malatya Turgut Özal Üniversitesi, Malatya, \\ Türkiye \\ serkan.metin@ozal.edu.tr
}

(Geliş/Received: 31/10/2020;

Kabul/Accepted: 27/11/2020)

Öz: İstatiksel birçok yöntem eksik değerlere sahip veri setleri üzerinde çalışma kapasitesine sahip değildir. Bu nedenle, girdi olarak yalnızca tam veriyi kabul eden modellerin tahmin performansı önemli ölçüde düşmektedir. Eksik verilerin tamamlanması bunun için veri analizlerinde önemli bir yere sahiptir. Bu çalışmada kullanılan veri seti üzerinde eksik olan verilerin tamamlanma probleminin çözümünde sezgisel optimizasyon yöntemi olan Benzetimli Tavlama Algoritması(BTA) kullanılmışır. Modern sezgisel teknikler, bir problem çözümünde, kendi yerel arama sistemleri ile en iyi sonuca ulaşmayı amaçlamaktadırlar. BTA performansını etkileyen en önemli değer başlangıç sıcaklık değeri (T0) olduğundan üç farklı sıcaklık değeri ile sonuçlar alınmıştır. To=100.000 değeri için $\% 68$, To=10.000 için $\% 51$ ve To=1.000 için \%46'lik bir başarı elde edilmiștir.

Anahtar kelimeler: Eksik veri, genetik algoritma, benzetimli tavlama algoritması, sezgisel yöntemler

\section{Completion of Missing Data with the Simulated Annealing Algorithm}

\begin{abstract}
Many statistical methods are not capable of working on datasets with missing values. Therefore, the forecasting performance of models that accept only full data as inputs drops significantly. For this reason, completing missing data has an important place in data analysis. Simulated Annealing Algorithm (SAA), a heuristic optimization method, was used to solve the problem of completing the missing data on the data set used in this study. Modern heuristic techniques aim to achieve the best results with their local search systems when solving a problem. Since the most important value affecting SAA performance is the initial temperature value $\left(\mathrm{T}_{0}\right)$, results have been obtained with three different temperature values. The following success rates were obtained: $68 \%$ for $\mathrm{T}_{0}=100.000,51 \%$ for $\mathrm{T}_{0}=10.000$ and $46 \%$ for $\mathrm{T}_{0}=1.000$.
\end{abstract}

Key words: Missing data, genetic algorithm, simulated annealing algorithm, heuristic methods

\section{Giris}

Gözlemsel verileri analiz ederken karşılaşılan en yaygın sorun eksik verilerdir. Gerçek veri kümeleri, çeşitli nedenlerden dolayı eksik verilerden oluşabilir [1]. Endüstri, tıp, ticaret ve bilimsel araştırmalar gibi [2] çok farklı kaynaklardan alınarak oluşturulan veri setlerinde eksik bilgiler ile karşılaşılabilir [3]. Toplanan verilerde tutarsızlıklar, hatalar, aykııı değerler ve eksik değerler gibi çeşitli kusurlar olabilir. Özellikle eksik veri oranı çok yüksek olan veri setlerinde, veri madenciliği veya makine öğrenmesi yöntemleri uygulanırken performans düşerken [4], istatiksel yöntemlerde ise eksik veriler ile tahmin yapmak oldukça sorunludur [5]. Girdi olarak yalnızca tam veriyi kabul eden algoritmalar eksik bir veri ile test edildiklerinde tahmin sonuçlarında önemli bir hata oluşmaktadır [6]. Bu nedenle, veri kalitesini artırmak için eksik veriler tamamlanmalıdır [7]. Eksik veri terminolojisi ilk kez Little ve Rubin tarafından kullanılmıştır [8]. Eksik değerleri ele almak için iyi bilinen ve hesaplama açısından basit birkaç yaklaşım vardır [1]:

- Eksik kayıtları göz ardı etmek.

- Boş değerleri manuel olarak doldurmak.

- Eksik veriyi ortalama veya medyan değeri ile doldurmak

Eksik değerlere yaklaşımlarda yapılacak ilk adım verinin örüntü varlığını incelenmektir [9]. Veri setinde yer alan eksik verilerin belli bir örüntü oluşturmadığı durumlarda farklı çözüm yöntemleri önerilmektedir [10]. Bu yöntemler silme, yaklaşık değer atama [11] ve model tabanlı atama yöntemleri olarak sinıflandırılabilir.

\footnotetext{
* Sorumlu yazar: serkan.metin@ozal.edu.tr Yazarların ORCID Numarası: 0000-0003-1765-7474
} 
Eksik verilerin değerlendirilmesindeki ilk yöntem kayıp veri olan kaydı yok saymaktır. Ancak eksik verinin çok olduğu ya da az kayıta sahip testlerde bu çözüm sonucu yanlış değerlere saptırmaktadır. Bu tür veri setlerinde eksik değer yerine yeni bir değer ataması yapmak çok daha iyi bir yaklaşımdır [12]. Bu gibi veri setlerindeki eksik sütun değerlerini tahmin etmek için hem sezgisel hem de model tabanlı gösterim yöntemleri kullanılır [13]. Eksik veri tamamlama ile ilgili kullanılabilecek yöntemler Şekil 1'de verilmiştir.

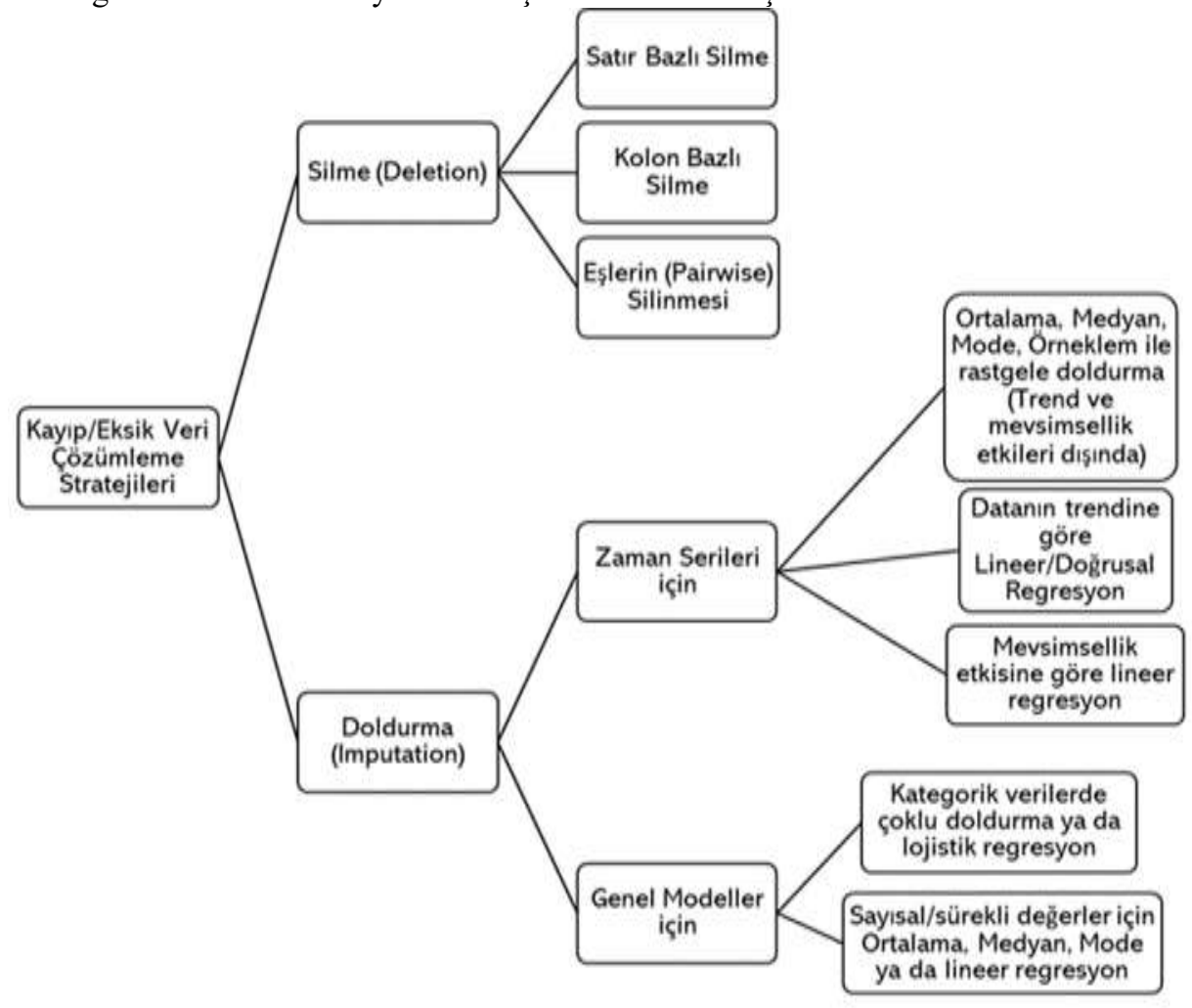

Şekil 1. Kayıp/Eksik Veri Çözümleme Stratejileri [14]

\section{Benzetimli Tavlama Algoritması}

Benzetimli Tavlama Algoritması (BTA), metallerin tavlama sürecinden esinlenerek [15] belirli bir maliyet fonksiyonunun küresel optimumuna yaklaşmak için tasarlanmış [16] sezgisel bir optimizasyon tekniğidir [17]. BTA, katıların 1sıtılması ve ardından yavaşça soğutulması esasına dayanır [18]. Isıtılan katıların sıcaklığı düştüğünde, katının iç parçacıkları her sıcaklıkta bir denge durumuna ulaşır [19]. BTA, 1sı arttıkça, en iyi yerel optimayı bulmak için komşu bölgeye gidecektir. Yavaş yavaş soğumaya başladığında ise en iyi yerel optimada durmaya çalışacaktır [20]. Bu yaklaşım, optimizasyon problemine en çözümü bulmak için kullanılır [21].

BTA, çözümde rastgele değişiklik yapabildiğinden yerel olarak optimal bir çözüme düşme olasılığı az olduğundan [22] geleneksel optimizasyon algoritmalarından daha güvenilir [23] ve problem için daha iyi sonuçlar verir [24]. BTA'nın yerel çözümlerde takılı kalmaması için bir P kabul olasılığı tanımlanır [25]:

$$
P=e^{-\Delta E / T}
$$

$\Delta \mathrm{E}$ farklı zaman aralıklarında malzemenin enerji değişimini, $\mathrm{T}$ ise sıcaklık değerini temsil eder. Başlangıç değeri olan T'nin değeri her yinelemede yavaş yavaş azalacaktır. BTA'nın kurallarına göre birincil çözüm tamamen rastgele oluşmaktadır [26]. Bu neden ile BTA'nın performansı büyük ölçüde başlangıç değerine bağlıdır. Başlangıç değerinin kalitesi zayıfsa, sonuç yetersiz olur [27]. Bu sebeple, aramaya yeteri kadar yüksek bir sıcaklık değeri ile başlamak gereklidir [28]. 


\section{Yöntem}

\subsection{Benzetimli Tavlama Algoritması Yöntemi}

Kirkpatrick 1983'de, kombinatoryal optimizasyon problemini çözmek için ilk kez BTA algoritmasını kullanmıştır [29]. BTA, pek çok farklı alandaki optimizasyon problemlerine kapsamlı bir şekilde uygulanan [30] etkili bir optimizasyon algoritmasıdır [31]. BTA yöntemine ait çözüm adımları [32] :

Adım 1: $\mathrm{s}=$ So kriterlere uyan herhangi bir çözüm

Adım 2: $\mathrm{t}=$ to başlangıç sıcaklık değeri.

Adım 3: $\alpha$ sıcaklık düşürme kuralını belirle.

$$
\begin{aligned}
& \mathrm{t}=\mathrm{t}-\alpha \\
& \mathrm{t}=\mathrm{t}^{*} \alpha \\
& \mathrm{t}=\mathrm{t} /(1+\beta \mathrm{t}) \quad \beta \text { rastgele bir say1 }
\end{aligned}
$$

Adım 4: İlk sıcaklıktan başlayarak, 5. Adımın n yinelemesini tekrarlayın ve ardından sıcaklığı $\alpha^{\prime}$ ya göre düşürlür.

Adım 5: N (s) çözümlerinin komşuluğunu göz önünde bulundurarak, çözümlerden birini seçin ve eski çözüm ile yeni komşu çözüm arasındaki maliyet farkı hesaplanır.

Adım 6: Eski ve yeni çözüm arasındaki maliyet farkı 0'dan büyükse yeni çözümü farkı 0'dan düşükse eski çözüm kabul edilir.

Uygulama için Türkiye’ye ait Sağlık Bakanlığı tarafından yayınlanan Covid-19 verileri kullanılmıştır. Veri setinden rastgele olarak değerler silinerek yeni veri seti oluşturulmuştur. Veri seti içerisindeki "Tanı Sayısı" sütununa ait veriler Şekil 2'de verilmiş olan programa ait arayüzde bulunan veri yükle seçeneği ile programa dahil edilmiştir.

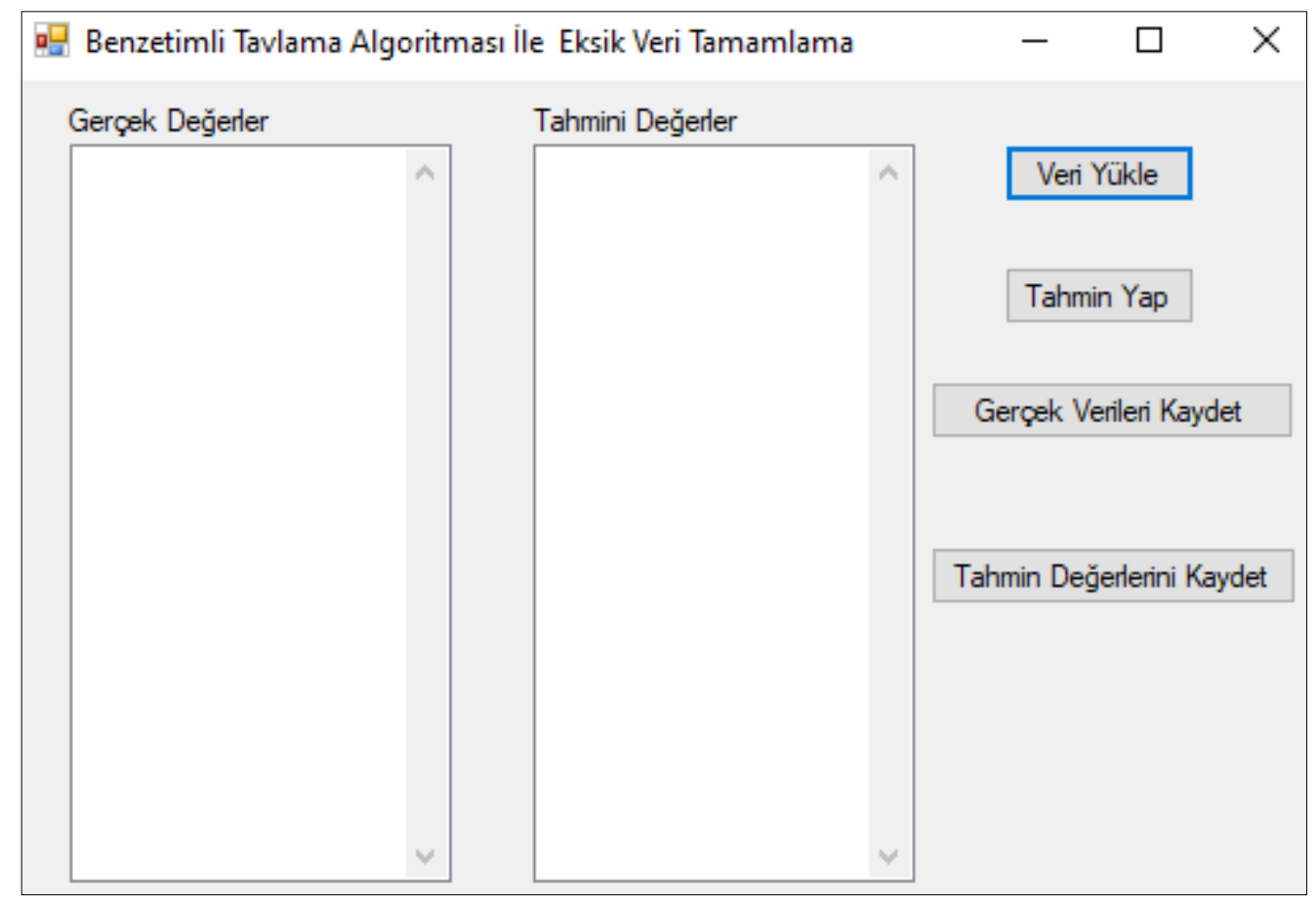

Şekil 2. Uygulama arayüzü

BTA ile tahmin işlemi başlatıldığında rastgele silinmiş olan satırdaki bilgiler var olan bilgilerden faydalanılarak tespit edilmiş ve eksik veriler tamamlanmaya çalışılmıştır. Uygulamada kullanılan BTA kod yapısı [33]:

1 Başlangıç sıcaklığık değeri $\mathbf{T}_{\mathbf{0}}$

2 İlk çözümü oluşturun $s$

3 While sonlandırma şartlar oluşmazsa 
$4 \mathbf{v}=\operatorname{Komşuseçim~}(\boldsymbol{s})$

$5 \boldsymbol{f}=$ Değerlendirme $(\boldsymbol{v})$

6 If $\boldsymbol{f}$ tatmin olasılıklı kabul kriteri

$7 \mathrm{~s}=\mathbf{v}$

8 Tavlama programına göre To güncelle

9 Son

10 Çıktı $s$

Eksik veri tamamlamada kullanılan BTA algoritmasının doğru sonuca ulaşmasındaki en büyük etken başlangıç sıcaklık değeridir. Çalışmamızda 3 farklı başlangıç sıcaklık değeri kullanılarak veri seti içerisindeki eksik veriler tamamlanmıştır. İlk örnek setinde başlangıç sıcaklı değeri sırası ile $100.000,10.000$ ve 1.000 olarak belirlenmiştir. Verilen başlangıç değerine göre elde edilen başarı oranları sırası ile \%68, \%51 ve \%46 olarak tespit edilmiştir. Tablo 1'de elde edilen sonuçlara ait değerler Tablo 1, Tablo 2 ve Tablo 3 'te verilmiştir.

Tablo 1. Başlangıç değeri=100.000 için bulunan değerler

\begin{tabular}{cccccc}
\hline Gerçek Değerler & $\begin{array}{c}\text { Tamamlanan } \\
\text { Değerler }\end{array}$ & Gerçek Değerler & $\begin{array}{c}\text { Tamamlanan } \\
\text { Değerler }\end{array}$ & Gerçek Değerler & $\begin{array}{c}\text { Tamamlanan } \\
\text { Değerler }\end{array}$ \\
\hline 343955 & 40974 & 370832 & 20163 & 38226 & 38226 \\
308069 & 45459 & 47 & 47 & 6 & 6 \\
349519 & 36538 & 170132 & 170132 & 186493 & 186493 \\
15679 & 15679 & 52167 & 52167 & 190165 & 190165 \\
155686 & 155686 & 158762 & 158762 & 20921 & 20921 \\
169218 & 169218 & 185245 & 185245 & 314433 & 48467 \\
222402 & 32177 & 23934 & 23934 & 366208 & 23892 \\
355528 & 32091 & 301348 & 42853 & 120204 & 120204 \\
1529 & 1529 & 138657 & 138657 & 209962 & 32707 \\
7402 & 7402 & 135569 & 135569 & 117589 & 117589 \\
244392 & 33198 & 127659 & 127659 & 82329 & 82329 \\
112261 & 112261 & 10827 & 10827 & 306302 & 43506 \\
42282 & 42282 & 284943 & 43786 & 98674 & 98674 \\
182727 & 182727 & 95591 & 95591 & 90980 & 90980 \\
126045 & 126045 & 281509 & 43376 & 86306 & 86306 \\
361801 & 27296 & 164769 & 164769 & 191657 & 191657 \\
114653 & 114653 & 174023 & 174023 & 261194 & 40525 \\
176677 & 176677 & 324443 & 46929 & 195883 & 195883 \\
197239 & 197239 & 237265 & 33296 & 156827 & 156827 \\
5 & 5 & 191 & 191 & 308069 & 47167 \\
\hline
\end{tabular}

Tablo 2. Başlangıç değeri=10.000 için bulunan değerler

\begin{tabular}{cccccc}
\hline $\begin{array}{c}\text { Gerçek } \\
\text { Değerler }\end{array}$ & $\begin{array}{c}\text { Tamamlanan } \\
\text { Değerler }\end{array}$ & $\begin{array}{c}\text { Gerçek } \\
\text { Değerler }\end{array}$ & $\begin{array}{c}\text { Tamamlanan } \\
\text { Değerler }\end{array}$ & $\begin{array}{c}\text { Gerçek } \\
\text { Değerler }\end{array}$ & $\begin{array}{c}\text { Tamamlanan } \\
\text { Değerler }\end{array}$ \\
\hline 201098 & 201098 & 56956 & 56956 & 223315 & 30702 \\
47029 & 47029 & 244392 & 35731 & 302867 & 46243 \\
312966 & 46360 & 373154 & 18105 & 219641 & 29610 \\
173036 & 173036 & 167410 & 167410 & 162120 & 162120 \\
\hline
\end{tabular}


Serkan METiN

\begin{tabular}{cccccc}
\hline 98 & 98 & 13531 & 13531 & 149435 & 149435 \\
368513 & 22123 & 255723 & 39016 & 299810 & 45579 \\
288126 & 42132 & 274943 & 41402 & 212993 & 31282 \\
179831 & 179831 & 353426 & 33648 & 278228 & 41696 \\
154500 & 154500 & 181298 & 181298 & 345678 & 39386 \\
159797 & 159797 & 233851 & 32973 & 139771 & 139771 \\
238450 & 34133 & 150593 & 150593 & 107773 & 107773 \\
1236 & 1236 & 148067 & 148067 & 283270 & 43570 \\
291162 & 44515 & 184031 & 184031 & 279806 & 40508 \\
289635 & 43708 & 163103 & 163103 & 152587 & 152587 \\
110130 & 110130 & 226100 & 31904 & 5698 & 5698 \\
131744 & 131744 & 104912 & 104912 & 244392 & 34501 \\
947 & 947 & 334031 & 51052 & 327557 & 51500 \\
193115 & 193115 & 224252 & 30606 & 267064 & 41780 \\
178239 & 178239 & 69392 & 69392 & 2433 & 2433 \\
218717 & 32032 & 320070 & 43990 & 30217 & 30217 \\
\hline
\end{tabular}

Tablo 3. Başlangıç değeri=1.000 için bulunan değerler

\begin{tabular}{cccccc}
\hline $\begin{array}{c}\text { Gerçek } \\
\text { Değerler }\end{array}$ & $\begin{array}{c}\text { Tamamlanan } \\
\text { Değerler }\end{array}$ & $\begin{array}{c}\text { Gerçek } \\
\text { Değerler }\end{array}$ & $\begin{array}{c}\text { Tamamlanan } \\
\text { Değerler }\end{array}$ & $\begin{array}{c}\text { Gercek } \\
\text { Değerler }\end{array}$ & $\begin{array}{c}\text { Tamamlanan } \\
\text { Değerler }\end{array}$ \\
\hline 332382 & 52642 & 188897 & 188897 & 292878 & 44735 \\
9217 & 9217 & 133721 & 133721 & 229891 & 32208 \\
224252 & 31958 & 65111 & 65111 & 221500 & 32105 \\
18 & 18 & 168340 & 168340 & 163942 & 163942 \\
175218 & 175218 & 225173 & 30574 & 166422 & 166422 \\
122392 & 122392 & 144749 & 144749 & 194511 & 194511 \\
227982 & 30644 & 302867 & 44622 & 18135 & 18135 \\
3629 & 3629 & 251805 & 36560 & 311455 & 46089 \\
236112 & 31669 & 253108 & 36994 & 253108 & 35652 \\
74193 & 74193 & 240804 & 32113 & 265515 & 41537 \\
199906 & 199906 & 227019 & 31977 & 239622 & 34420 \\
146457 & 146457 & 214993 & 32280 & 215940 & 30832 \\
230873 & 32390 & 1 & 1 & 171121 & 171121 \\
211981 & 31472 & 124375 & 124375 & 129491 & 129491 \\
187685 & 187685 & 137115 & 137115 & 228924 & 29455 \\
240804 & 33406 & 670 & 670 & 241997 & 32406 \\
157814 & 157814 & 153548 & 153548 & 323014 & 50459 \\
250542 & 37489 & 274943 & 42700 & 359 & 359 \\
1872 & 1872 & 248117 & 36381 & 271705 & 42406 \\
265515 & 38660 & 223315 & 32033 & 288126 & 44198 \\
\hline
\end{tabular}




\section{Sonuçlar}

$\mathrm{Bu}$ çalışmada veri madenciliği, makine öğrenmesi ve istatiksel yöntemlerde kullanılan veri setleri içerisindeki eksik verilerin sezgisel optimizasyon tekniği olan BTA ile tamamlanması amaçlanmıştır. Çalışma kapsamında literatür incelenerek eksik veri tamamlama yaklaşımları belirlenmiş̧tir. Eksik veri tamamlama yöntemleri kullanılırken var olan verilerden faydalanmak genel bir yaklaşımdır. BTA'nın tercih edilmesinin sebebi algoritmanın yerel optimum noktalarında takılı kalmamasıdır.

BTA incelendiğinde başlangıç değeri başarı oranını doğrudan etkilediğinden uygun bir başlangıç değerinin seçilmesi gerekmektedir. Algoritma bir optimizasyon yöntemi olduğu için uygulanacak olan veri setindeki eksik verilerin neden kaynaklandığı belirlenmelidir. Eksik veriye ait örüntü çıkarıldıktan sonra yöntem uygulanmalıdır.

Elde edilen sonuçlara bakıldığında en yüksek olarak \%68'lik bir başarı yakalanmıştır. Başarı oranını artırabilmek için optimum başlangıç değerini ayarlayabilecek yöntemler geliştirilebilirse eksik veri tamamlama konusunda önemli katkılar sağlayacağı düşünülmektedir. BTA algoritmasının dezavantajı ise soğuma işleminin uzun sürmesidir.

\section{Kaynaklar}

[1]. Sefidian A.M, Daneshpour N. Estimating missing data using novel correlation maximization based methods, Applied Soft Computing Journal, 2020; 91: 106249.

[2]. Rahman M.G, Islam M.Z. Missing value imputation using a fuzzy clustering-based EM approach, Knowl. Inf. Syst. 2016; 46 (2): 389-422.

[3]. Gopalakrishnan R, Guevara C.A, Akiva M. Combining multiple imputation and control function methods to deal with missing data and endogeneity in discrete-choice models, Transportation Research Part B, 2020; 142: 45-57.

[4]. Ye C, Wang H, Li J, Gao H, Cheng S. Crowdsourcing-Enhanced missing values imputation based on Bayesian network, in: International Conference on Database Systems for Advanced Applications, Springer; 2016: 67-81.

[5]. Mercaldo S.F, Blume J.D. Missing data and prediction: the pattern submodel, Biostatistics, 2020; 21(2): $236-252$.

[6]. Zhiyong C, Longfei L, Ziyuan P. Yinhai Wang Graph Markov network for traffic forecasting with missing data, Transportation Research Part C; 2020.

[7]. Qin Y, Zhang S, Zhu X, Zhang J, Zhang C. POP algorithm: Kernel-based imputation to treat missing values in knowledge discovery from databases, Expert Syst. Appl., 2009; 36 (2): 2794-2804.

[8]. Molenberghs G, Thijs, H, Jansen I, Beunckens, C, Kenward, M.G, Mallinckrodt, C, Carroll, R.J. Analyzing Incomplete Longitudinal Clinical Trial Data; 2004.

[9]. Sayın A, Yandı A, Oyar E. Kayıp Veri ile Baş Etme Yöntemlerinin Madde Parametrelerine Etkisinin İncelenmesi, Journal of Measurement and Evaluation in Education and Psychology, 2017; 8(4): 490-510.

[10]. Carpita M, Manisera M. On the imputation of missing data in surveys with Likert-type scales. Journal of Classification, 2011; 28(1): 93-112.

[11].Demir E, Parlak B. Türkiye'de eğitim araştırmalarında kayıp veri sorunu. Eğitimde ve Psikolojide Ölçme ve Değerlendirme Dergisi, 2012; 3(1): 230-241.

[12].Sezgin E, Çelik Y.Veri Madenciliğinde Kayıp Veriler İçin Kullanılan Yöntemlerin Karşılaştırılması, Akademik Bilişim Konferansı, Akdeniz Üniversitesi, 2013.

[13].Little, R.J.A., Rubin, D.B. Statistical Analysis with Missing Data: Second Edition. John Wiley and Sons, 2002

[14]. Şener Y. Veri Biliminde Eksik/Kayıp Verilere Yaklaşım Stratejileri ve Python (Pandas) Uygulaması, 2020

[15]. Min L, Yue C, Xiaojing S, Zhishan Z, Xiaoxiao Z, Xiuyu Z, Jun G. Simulated annealing-based optimal design of energy efficient ternary extractive dividing wall distillation process for separating benzeneisopropanol-water mixtures, , Chinese Journal of Chemical Engineering,2020.

[16]. Xiangzhen Z, Sanjiang L, Yuan F. Quantum Circuit Transformation Based on Simulated Annealing and Heuristic Search, , Transactions on Computer-Aided Design of Integrated Circuits and Systems, 2020.

[17]. Moriguchi K. Acceleration and enhancement of reliability of simulated annealing for optimizing thinning schedule of a forest stand, Computers and Electronics in Agriculture, 2020.

[18].Kirkpatrick S, Gelatt C.D, Vecchi, M.P. Optimization by Simulated Annealing. Science new series, 1983; 220(4598): 671-680.

[19]. Songsheng T, Minjun P, Genglei X, Ge W, Cheng Z. Optimization design for supercritical carbon dioxide compressor based on simulated annealing algorithm, Annals of Nuclear Energy, 2020.

[20]. Asrul S.R, Ikram M, Mohd R. Mohd A.A. Energy Management Strategy of HEV based on Simulated Annealing, Int. J. of Integrated Engineering, 2020; 12(2): 30-37.

[21].Lizhong Z, He M, Wei Q, Haiyan L. Protein structure optimization using improved simulated annealing algorithm on a three-dimensional AB off-lattice model, Computational Biology and Chemistry, 2020.

[22].Jin C, Bin W. Flocking Control of Mobile Robots via Simulated Annealing Algorithm, Proceedings of the 39th Chinese Control Conference, 2020; 3931- 3935.

[23]. Tatsuya K, Hideharu K, Hiroyuki N, Tatsuhiro T. Using simulated annealing for locating array construction, Information and Software Technology 126, 2020. 
[24]. Attiya I, Elaziz M, Xiong S. Job Scheduling in Cloud Computing Using a Modified Harris Hawks Optimization and Simulated Annealing Algorithm, Computational Intelligence and Neuroscience, 2020.

[25].Hanine M, Benlahmar E H.A Load-Balancing Approach Using an Improved Simulated Annealing Algorithm, J Inf Process Syst, 2020;16:132-144.

[26].Jafari H, Ehsanifar M, Sheykhan A. Finding Optimum Facility's Layout by Developed Simulated Annealing Algorithm, Int. J. Res. Ind. Eng., 2020; 9(2): 172-182.

[27]. İlhan İ. A population based simulated annealing algorithm for capacitated vehicle routing problem, , Turk J Elec Eng \& Comp Sci, 2020; 28: 1217-1235.

[28]. Cayıroglu I. İleri Algoritma Analizi, 2020.

[29].Xianze M, Yunpeng F, Junsheng Y. Estimating solubilities of ternary water-salt systems using simulated annealing algorithm based generalized regression neural network, Fluid Phase Equilibria, 2020.

[30].Cunha M, Marques J. A New Multiobjective Simulated Annealing Algorithm-MOSA-GR: Application to the Optimal Design of Water Distribution Networks, Water Resources Research, 2019.

[31].Minghao G, Chunbo W, Baicheng L, Bin S. Yuanshen Huang Design and implementation of a Placido disk-based corneal topographer optical system based on aberration theory and simulated annealing algorithm,Optics Communications 475, 2020.

[32].Liang F. Optimization Techniques Simulated Annealing A popular method for optimizing model parameters, 2020.

[33]. Tsai C.W, Hsia CH, Yang SJ, Liu SJ, Fang ZY. Optimizing hyperparameters of deep learning in predicting bus passengers based on simulated annealing, Applied Soft Computing Journal 88, 2020. 